\title{
Uma interpretação analítico-comportamental de aspectos culturais e simbólicos da fogueira de São João*
}

\section{A behavioral-analytic interpretation of cultural and symbolic aspects of Saint John's bonfire}

\section{Una interpretación analítico-comportamiental de los aspectos culturales y simbólicos de la hoguera de San Juan}

\section{Anderson Jonas das Neves ${ }^{1}$}

[1] Universidade Federal de São Carlos| Título abreviado: Fogueira de São João: prática cultural e redes simbólicas | Endereço para correspondência: R. Christiano Pagani, 8-51, 42F, Jardim Contorno. CEP: 17047-144, Bauru, SP, Brasil I Email: filosofoajn@gmail.com I DOI: 10.18761/PAC.2016.035

\begin{abstract}
Resumo: As festas juninas são comemorações populares que foram historicamente relacionadas à fecundidade da terra, às práticas agrárias e ao culto a São João Batista. Um dos elementos mais distintivos dessas festividades é a fogueira de São João. Investigações em Sociologia, Antropologia e Folclore têm esclarecido as origens da fogueira na noite de São João e as relações dessa com as práticas de alguns povos. O presente artigo propõe que a fogueira junina pode ser tratada historicamente como uma prática cultural e um símbolo (ou uma rede relacional simbólica) e, como tal, ser passível de uma análise comportamental. Por meio da seleção de estudos sobre o tema, foi feito um levantamento histórico e buscou-se identificar e analisar algumas contingências e relações simbólicas que perpassaram a fogueira junina. A análise de alguns eventos históricos permite especular que, da chama pagã nos rituais de fertilidade ao fogo cristão de São João, as funções e as redes relacionais simbólicas da fogueira mudaram e configuraram recursos para o controle do comportamento dos indivíduos. Esse trabalho explora algumas possibilidades de interpretação analítico-comportamental da fogueira junina e sugere uma interface da Análise do Comportamento com as ciências humanas para estudar as práticas populares.
\end{abstract}

Palavras-chave: festas juninas, fogueira de São João, análise do comportamento, prática cultural, redes simbólicas.

\footnotetext{
* Nota do Autor

Agradeço ao prof. Dr. Júlio Cesar de Rose e à profa. Dra. Maria Stella Coutinho de Alcântara Gil pelas profícuas discussões nas aulas da pós-graduação da UFSCar, as quais possibilitaram lançar essa proposta de trabalho. Agradeço também ao Doutorando Me. André Luíz Ferreira pelas importantes contribuições e pela leitura cuidadosa.
} 
Abstract: The june festivals are popular celebrations that were historically related to the soil fertility, the agricultural practices and the cult to St. John. One of the most distinctive elements of these festivities is the bonfire of St. John. Researches in Sociology, Anthropology and Folklore has clarified the origins of the bonfire on the night of St. John and the relations this with the practices of the same civilizations. The present article proposes that the june bonfire can be treated historically as a cultural practice and a symbol (or symbolic relational network) and, thereby, be subject to a behavioral analysis. Through of the selection of studies on the thematic, a historical survey was made and was identified and analyzed some contingencies and symbolic relations that permeated the June fire. The analysis of the same historic events allow speculate that, from pagan flame in fertility rituals to christian fire of St. John, the functions and symbolic relational networks of bonfire changed and configured helpful resources for controlling the behavior of individuals. This study explores same possibilities of the interpretation analytic-behavioral of the june bonfire and suggests a interface between Behavior Analysis with the human sciences to study popular practices.

Keywords: june festivals, bonfire of St. John, behavior analysis, cultural practice, symbolic networks.

Resumen: Los festivales juninos son fiestas populares que históricamente estaban relacionadas con la fertilidade, las prácticas agrícolas y el culto a San Juan. Uno de los elementos más característicos de las fiestas es el hoguera de San Juan. La investigacións en Sociología, Antropología y Folclore ha aclarado el origen de hoguera de San Juan y la relación de este con las prácticas de algunas civilizaciones. En este artículo propone que el hoguera junina puede ser tratado históricamente como una práctica cultural y un símbolo (o una redes de relaciones simbólicas), y como tal, ser objeto de una análisis comportamiental. Por medio de la selección de los estudios sobre el tema, un estudio histórico fue hecho y trató de identificar y analizar algunas contingencias y relaciones simbólicas que impregnaron el fuego junio. El análisis de algunos acontecimientos históricos nos permite especular que, fuego del los ritos paganos de la fertilidad ao fuego christian el San Juan, las funciones y las redes de relaciones simbólicas de hoguera cambiaron y se configuran estrategias útiles para controlar el comportamiento de los individuos. Este artículo explora algunas posibilidades de interpretación comportamiento analítico de fuego Junina y sugiere un análisis del comportamiento de la interface con las ciencias humanas para estudiar las prácticas populares.

Palabras-clave: festivales junina, hoguera del San Juan, análisis del comportamiento, prácticas culturales, las redes simbólicas. 
"Chegou a hora da fogueira/É noite de São João/O céu fica todo iluminado..." (Cascudo, 2000; Rangel, 2008). Cantigas como essa fazem parte do repertório musical das festividades juninas e evidenciam a fogueira como um dos elementos mais centrais e distintivos dessas comemorações. A prática de atear a fogueira nos dias 23 e/ou 24 de junho é um marco dos festejos juninos e tem como objetivo venerar e rememorar o nascimento de São João Batista (Cascudo, 1956, 2000; Chianca, 1991, 2007, 2009; Trigueiro, 1995). Por esse motivo, tem sido especialmente chamada de "fogueira de São João" (Rangel, 2008).

A perspectiva religiosa tem tratado a fogueira de São João como uma prática devocional, de tradição católica e que visa reverenciar esse santo (Chianca, 1991). Algumas investigações folclóricas, sociológicas e antropológicas têm contribuído ao trazer uma compreensão mais ampla e precisa sobre as origens dessa prática e do como a fogueira junina foi atrelada deliberadamente a questões produtivas, sociais e simbólicas ao longo da História (Candido, 2001; Cascudo, 1956, 2000; Chianca, 2007, 2009; Lima, 1971; Rangel, 2008).

Uma possibilidade de analisar e interpretar a fogueira de São João seria aportada pela Análise do Comportamento. Por meio da descrição e análise funcional dos comportamentos, inclusive no âmbito da cultura (Catania, 1999; Skinner, 1953; Todorov, Martone \& Moreira, 2005), uma perspectiva analítico-comportamental poderia trazer considerações relevantes sobre processos comportamentais envolvidos na fogueira junina.

\section{Considerações iniciais para uma análise comportamental da cultura}

A Análise do Comportamento tem adotado os pressupostos do Behaviorismo Radical de B. F. Skinner e se proposto a identificar, descrever e analisar o comportamento, as suas variáveis envolvidas e as relações funcionais que se estabelecem entre classes de estímulos e classes de respostas (Catania, 1999; Skinner, 1953). Os comportamentos considerados simples até os mais complexos como a linguagem, a cognição e a interação social - podem ser passíveis de uma descrição e inves- tigação comportamental, a partir da tríplice contingência como unidade de análise (Catania, 1999; Skinner, 1953, 1981).

No caso da cultura, Skinner $(1953,1974)$ definiu-a como um conjunto de contingências de reforço mantidas por grupos sociais. As bases lançadas por Skinner $(1953,1974,1981,1986)$ permitiram que a cultura fosse tomada como objeto de estudo operante e que fossem empreendidos esforços teóricos e experimentais para investigá-la (Guerin, 1994; Sampaio \& Andery, 2010; Todorov, Martone, $\&$ Moreira, 2005). Os estudos analítico-comportamentais abordaram a cultura em, pelo menos, dois aspectos (Andery, 2011): como variável independente, ou seja, como um conjunto de variáveis ou componentes que determinam o comportamento individual; e como variável dependente, sendo a cultura tomada um fenômeno a ser esclarecido em si, para depois ser analisado como determinante do comportamento dos indivíduos; essa discussão pode ser aprofundada em Andery (2011).

Nessa direção, as propostas de Glenn (1986, 1989) em torno do conceito de metacontingência proporcionaram à Análise do Comportamento um caminho para se investigar os fenômenos culturais (Todorov, Martone, \& Moreira, 2005). Em recente revisão, Gleen e colaboradores (2016) propuseram a metacontingência como uma relação contingente entre (a) as contingências comportamentais entrelaçadas recorrentes com um produto agregado e (b) as consequências do ambiente selecionador.

Contingências entrelaçadas envolvem interações entre contingências de reforçamento dos indivíduos, em que as classes de operantes e os produtos comportamentais de cada membro funcionam como ambiente para o comportamento dos demais; logo, os operantes de cada pessoa desempenham duplo papel: de ação e de ambiente para a ação de outros (Gleen, 1989; Sénéchal-Machado \& Todorov, 2008). As contingências entrelaçadas podem ser recorrentes e vir a gerar produtos - o que chamamos de produto agregado - que são resultantes dos operantes inter-relacionados recorrentemente (Gleen, 1989; Gleen et al., 2016). O ambiente externo, por sua vez, funciona como recipiente desse produto agregado e seleciona essas contingências entrelaçadas (Mallot \& Glenn, 2006). Um exemplo didático de metacontingência seria o lançamento de carro: 
o entrelaçamento recorrente das contingências entre funcionários da empresa automobilística - da concepção até a produção - gera um produto final (carro novo), cuja possibilidade de compra pelos consumidores (ambiente selecionador) pode selecionar a continuidade da fabricação desse carro.

As propostas de Gleen $(1986,1989)$ provocaram debates e proporcionaram um campo fértil de discussões teórico-conceituais para a análise comportamental da cultura (Todorov, Martone, \& Moreira, 2005; Carrara \& Zilio, 2015). Um dos debates tem sido quanto a unidade de análise para se estudar fenômenos culturais. De um lado, Biglan (1995), Guerin (1992, 1994) e Carrara e Zilio (2015) tem discutido que a análise comportamental da cultura não precisa se valer de novas unidades conceituais e que a tríplice contingência permitiria estudar os fenômenos culturais. Por outro, Glenn $(1986,2003$, 2004), Andery, Micheletto e Sério (2005), Sampaio e Andery (2010), Todorov, Martone e Moreira (2005) tem apontado a contingência como uma unidade insuficiente para analisar relações complexas - como as que ocorrem na cultura - e que a metacontingência configura uma unidade analítica mais pertinente para se explicar a evolução e manutenção de unidades culturais. O presente trabalho não pretende defender uma ou outra posição, mas apontar as possiblidades da cultura ser analisada via contingência ou metacontingência.

Para além das questões teóricas, o atual desafio dessa área têm sido planejar condições empíricas e sistemáticas para se investigar a cultura (Andery, 2011). Nesse contexto, alguns estudos brasileiros têm protagonizado métodos e condições experimentais para estudar os processos culturais (Vichi, 2004; Todorov, Martone, \& Moreira, 2005). Tais avanços metodológicos lançaram perspectivas para estudos "fora do laboratório", como experimentos naturais ou quase-experimentos (Andery, 2011).

\section{As práticas culturais na análise comportamental da cultura}

De modo geral, as relações comportamentais de interesse da análise comportamental da cultura são as práticas culturais. Dittrich (2004) sintetizou-as conceitualmente como "operantes (ou conjuntos de operantes ligados e que podem envolver contingências entrelaçadas) reforçados por certa cultura e transmitidos entre as sucessivas gerações desta cultura”. Brunkow (2014) fez uma revisão da análise da cultura em Skinner e em Gleen, destacando que as práticas culturais podem ser definidas em operantes transmitidos, operantes similares e operantes com produto agregado. Operantes transmitidos são comportamentos que foram selecionados por consequências individuais e posteriormente transmitidos, por alguma forma de comportamento social, intra ou entre gerações. Já os operantes similares são definidos pelas recorrentes ocorrências em diferentes pessoas e que podem ser derivados de contingências individuais, sem ter transmissão geracional. Operantes que geram produto agregado, por sua vez, podem envolver (ou não) contingências entrelaçadas; quando não envolvem e são recorrentes, há uma macrocontingência; se envolvem entrelaçamento, podem ser descritos como sem ou com recorrência, sendo o último definido como metacontingência.

Skinner (1981) sugeriu que os mesmos princípios de variação e seleção que operam sobre os genes seriam, de modo análogo, aplicados às práticas envolvidas na cultura. Assim, uma variação a nível da cultura poderia envolver variações nas práticas culturais, que podem ser randômicas, tal como acontece nos genes (Skinner, 1981; de Rose, 2016). O surgimento ou a mudança nas práticas pode decorrer também do contato dos indivíduos com outras culturas, em que uma cultura adquire práticas da outra (de Rose, 2016).

As práticas podem ser implementadas de modo mais deliberado, quando o grupo observa as contingências e prescreve regras que são transmitidas entre gerações (Baum, 2000; Guerin, 1992, 1994). O desenvolvimento do comportamento verbal tornou possível a transmissão de práticas culturais entre gerações e a prescrição de regras que controlassem os comportamentos do grupo (Baum, 2000). As regras oferecem ganhos para a cultura na medida em que estabelecem elos entre os comportamentos presentes e as consequências relevantes e remotas (Skinner, 1969). Algumas agências, como governo e religião, têm exercido controle por meio de regras que interagem com as contingências e permitem o engajamento nos comportamentos esperados (Guerin, 1992, 1994; Skinner, 1953). 
Skinner $(1969,1981)$ propôs que práticas culturais tendem a permanecer quando contribuem para a sobrevivência de uma dada cultura. Essa perspectiva selecionista permitiu que as consequências relevantes para a seleção das práticas tivessem uma atenção especial na análise da cultura (Sampaio \& Andery, 2010; Todorov, Martone, \& Moreira, 2005).

Mallot e Glenn (2006) propuseram que as práticas envolvendo metacontingências são selecionadas por consequências culturais que afetam as contingências entrelaçadas recorrentes e o produto agregado. Já na macrocontingência, os efeitos do ambiente selecionador não funcionam como consequência para os operantes individuais recorrentes; logo, essas práticas são selecionadas por consequências individuais e podem, quanto mais forem difundidas, gerar um efeito cumulativo (Mallot \& Glenn, 2006).

Guerin $(1994 ; 1998 ; 2004)$ colaborou nessa discussão e destacou a relevância das consequências sociais nas práticas culturais. Algumas consequências sociais - ainda que variáveis, sutis e remotas (atrasadas) - podem vir a selecionar e manter comportamentos de baixa probabilidade entre os indivíduos (Guerin, 1994; Melo \& de Rose, 2012). Práticas religiosas, por exemplo, podem ser selecionadas e mantidas por consequências sociais - como abrigo e suporte social -, e vir a trazer benefícios a longo prazo para a cultura.

O Materialismo Cultural ${ }^{1}$ (Harris, 2001, 2007) traz uma visão selecionista de cultura e tem pontos de aproximação com a Análise do Comportamento (Melo \& de Rose, 2012). As práticas culturais em níveis estruturais (como governo) e superestruturais (como religião), embora distintas, podem ser selecionadas pelos efeitos que produzem sobre a infraestrutura (produção e sobrevivência), tornando-a mais eficiente (Harris, 2001, 2007).

1 Segundo Harris $(2001,2007)$, as práticas culturais podem compor níveis distintos e se organizar em infraestrutura, estrutura e superestrutura. A infraestrutura engloba práticas que promovem a produção de recursos, a subsistência, a reprodução e a manutenção do grupo; práticas que minimizam as ameaças à sobrevivência também compõem esse nível. Já a estrutura abrange os sistemas governamentais e econômicos. A superestrutura, por sua vez, engloba as práticas da religião, da arte e da ciência.

\section{As redes simbólicas na análise comportamental da cultura}

Os homens criaram "teias de significados" para lidarem com o mundo (Geertz, 1973). A capacidade simbólica permitiu que desenvolvêssemos sistemas arbitrários e complexos que estão presentes nos diversos domínios da cultura: desenvolvemos linguagem, criamos códigos linguísticos, produzimos arte, geramos mitos e fazemos ciência (de Rose, 2016).

A cultura pode ser tomada como "um universo de símbolos que permite aos indivíduos de um grupo interpretarem a experiência e guiarem suas ações" (Geertz, 1973, p.52). Para Geertz (1973), os símbolos são "quaisquer objetos, acontecimentos ou relações que servem como vínculo" para direcionar atitudes (Geertz, 1973, p.102). Nessa lógica, os símbolos circunscreveriam eventos que exercem controle sobre o comportamento dos indivíduos.

A Análise do Comportamento tem esclarecido como os símbolos afetam o comportamento, principalmente a partir das contribuições de Sidman e colaboradores. A proposta do modelo das relações de equivalência (Sidman, 1994; 2000) tem fornecido subsídios operacionais para se estudar as relações simbólicas e mostrado experimentalmente como os símbolos podem controlar o comportamento, sob determinados contextos (de Rose \& Bortoloti, 2007).

Símbolos podem ser criados quando eventos dissimilares, arbitrariamente relacionados e que compartilham um elemento comum (pelo menos) estabelecem relações de equivalência (Sidman, 1994; de Rose \& Bortoloti, 2007). Logo, redes relacionais entre estímulos, quando estabelecem relações de equivalência, tornam-se, redes relacionais simbólicas.

Essas redes relacionais simbólicas podem ser programadas experimentalmente em laboratório. Diversos procedimentos são empregados para se estabelecer relações arbitrárias entre estímulos que compartilhem de elementos comuns e, em seguida, são aplicados testes que verificam as propriedades da equivalência (Sidman, 1994; de Rose \& Bortoloti, 2007). As contingências que produzem relações de equivalência permitem também a emergência de relações arbitrárias entre estímulos que 
não foram diretamente treinadas. Uma rede simbólica (ou seja, uma rede de relações de equivalência) pode ser criada no contexto experimental usando, por exemplo, estímulos falado /jablko/, a fruta maçã e o texto JABLKO: podemos ensinar diretamente relações arbitrárias entre /jablko/ falado e a maçã e entre essa palavra falada e o JABLKO escrito, aplicar os testes formais e verificar relações derivadas entre JABLKO escrito e a maçã.

Os estímulos que participam de redes relacionais simbólicas podem atuar - em alguns contextos - como substitutos dos demais estímulos da rede, de modo a passarem "a ser tratados virtualmente como se fosse o estímulo que ele simboliza" (de Rose, 2016). Quando as relações de equivalência são estabelecidas, as funções exercidas por um dado estímulo passam a ser compartilhadas pelos outros estímulos da classe (Dougher et al., 1994). Esse fenômeno tem sido chamado de transferência de função (de Rose \& Bortoloti, 2007).

De Rose (2016) discutiu a importância dos símbolos para as culturas e como elementos nela presentes podem ser caracterizados por redes relacionais simbólicas. Nessa direção, algumas contingências especialmente arranjadas pelas culturas podem produzir redes simbólicas e, por conseguinte, configurar recursos úteis no controle de várias práticas humanas. Um exemplo descrito por de Rose (2016) seriam as atitudes políticas: falar de "esquerda", o Partido dos Trabalhadores (PT), a estrela (distintivo do $\mathrm{PT}$ ), a cor vermelha, o número 13 e o ex-presidente Lula pode configurar uma rede simbólica; e a atitude dos grupos em relação a essa rede pode depender, por exemplo, da filiação política. Esse exemplo sugere que a investigação de como as pessoas em grupo reagem a redes simbólicas (da cultura) pode configurar um campo promissor para a análise comportamental da cultura.

O termo "atitude" tem sido usado para tratar de comportamentos envolvendo redes simbólicas desse tipo (Barnes \& Grey, 1996; Biglan, 1995). Barnes e Grey (1996) demonstraram experimentalmente como as atitudes são formadas. Por meio de um treino de relações arbitrárias, os participantes desse estudo formaram duas classes de estímulos equivalentes com sílabas sem sentido (A1B1C1 e A2B2C2). Após, foram expostos dois vídeos, sendo uma cena sexual rotulada por B1, enquanto a cena religiosa designada por $\mathrm{B} 2$. Na fase final do estudo, os participantes deveriam categorizar vídeos como "bons" ou "ruins" usando demais sílabas do treino (A1, C1, A2 e C2). Todos responderam consistentemente e demostraram a transferência de função entre os estímulos: aqueles que atribuíram cenas sexuais como "boas" categorizam-nas usando A1 e $\mathrm{C} 1$, enquanto as cenas religiosas tidas como "ruins" foram rotuladas por A2 e C2, e vice-versa. Os resultados sugerem que atitudes podem ser formadas com base em redes relacionais simbólicas, sem que haja uma história direta com os eventos.

Algumas contingências sociais podem ser especialmente arranjadas para que os indivíduos lidem com aspectos do mundo com base em redes relacionais (Barnes \& Grey, 1996; Biglan, 1995; Mizael, Santos \& de Rose, 2016). Pesquisas tem demostrado que atitudes como preconceito (de Carvalho \& de Rose, 2014) e rivalidades entre clubes esportivos (Haydu, Camargo, \& Bayer, 2015) podem estar sob controle de redes simbólicas.

\section{As festas juninas e a possibilidade de análise comportamental da fogueira de São João}

As festas populares estão presentes em todas as culturas e são demarcadas, dentre os diversos componentes festivos, por marcos distintivos que as evidenciam e definem (Amaral, 1998). Esses elementos distintivos podem ser descritos como eventos (tais como situações e objetos) carregados de sentido histórico e simbólico e que visam intensificar e particularizar uma dada festa (Amaral, 1998). A árvore enfeitada no Natal e os fogos no Ano Novo são exemplos de elementos distintivos.

No Brasil, as festas juninas perfazem uma das comemorações mais populares, com diversas expressões nas várias regiões do país (Chianca, 1998). Trazida durante a colonização portuguesa, essas festas remontam aos antigos festivais agrários da Europa que reverenciavam as divindades da fertilidade. A cristianização do Império Romano fez com que esses festejos fossem ajustados e atribuídos à São João Batista (Rangel, 2008). Das festas pagãs até a solenidade cristã, um dos elementos distintivos e marcantes dessas festas foi a fogueira. 
Antropólogos, sociólogos e folcloristas tem desenvolvido frentes de pesquisa para estudar as festas juninas e os elementos distintivos, como a fogueira. Uma frente tem trabalhado por um viés histórico: por meio da seleção e análise de eventos históricos, estudos tem descrito como essas festas foram concebidas e quais as funções que a fogueira e outros marcos distintivos exerceram sob a produção, a política e a religião (Amaral, 1998). Outra frente tem investido nos aspectos simbólicos; assim, as músicas, os objetos, as vestes, as danças e os ritos foram tomados como objetos de pesquisa. O interesse dessa frente tem sido o efeito simbólico sobre o grupo, ou seja, o modo como as pessoas lidam com os elementos e marcos distintivos das festas juninas (Amaral, 1998).

A proposta desse trabalho é realizar um exercício interpretativo sobre um importante marco distintivo da festa junina, que é a fogueira de São João. Por meio da seleção de fatos históricos, proponho tratar a fogueira junina como uma prática cultural e como um símbolo (ou rede relacional simbólica) e, como tal, ser descrita e analisada em uma perspectiva analítico-comportamental.

\section{Método}

\section{Procedimento de coleta}

$\mathrm{O}$ método foi organizado por uma sequência de passos para se extrair os fatos históricos considerados relevantes. Os estudos da literatura que trataram sobre a fogueira junina foram tomados como fontes históricas nesse estudo; essa opção tem sido indicada por alguns cientistas sociais (Amaral, 1998), dada a dificuldade real de acesso a fontes históricas mais diretas, como documentos oficiais e materiais arqueológicos; ainda, esses estudos podem ter um status de fonte histórica indireta, no sentido de descrevem aspectos históricos, embora não constituam como registros diretos de natureza histórica/arqueológica e implicarem, algumas vezes, no contato com especulações dos autores. Sénéchal-Machado e Todorov (2008) adotaram fontes históricas diretas para se estudar campanhas de respeito à faixa de pedestre de Brasília em meados de 1990. Nessa direção, o presente estudo percorreu um caminho metodológico semelhante ao
Sénéchal-Machado e Todorov (2008) para elencar dados históricos, contudo usando de fontes indiretas (trabalhos que tratavam da temática).

Inicialmente, procedeu-se a busca de materiais científicos relacionados ao tema (artigos, dissertações, teses, livros e textos de divulgação científica) por meio da consulta a três bases de dados virtuais, quais sejam, Google Acadêmico, Periódicos CAPES e o Banco de Teses e Dissertações da CAPES. A busca foi realizada no período de março a setembro de 2016 e adotou os descritores "fogo", "fogueira", "junina" e "São João", que foram combinados em expressões de dois termos, quais sejam, "fogo" [e] "junina", "fogo" $[e]$ "São João", "fogueira”[e]“junina” e "fogueira”[e]“São João". Os resultados foram compilados e integraram um banco de dados; os materiais sugeridos por mais de uma expressão (ou seja, repetidos) foram contabilizados como um único e os demais foram excluídos.

No segundo momento, os títulos e os resumos foram lidos. O critério para selecionar os trabalhos de interesse foi que apresentassem os temas "festas juninas", "fogueira junina” ou "fogueira de São João" no título ou no resumo. Não foram consideradas para a análise as informações adicionais dos textos, como área, mediação teórica, tipo e ano de publicação.

A etapa final consistiu na leitura integral de todos trabalhos selecionados na etapa anterior. Os fatos históricos que os autores julgavam relevantes (para estudar e entender a fogueira junina) foram registrados em uma planilha; para cada evento histórico, foram anotadas também algumas considerações dos autores. O presente estudo elencou apenas os fatos históricos que tivessem descritos em, pelo menos, três trabalhos diferentes; esse critério foi aplicado por considerar que, para um evento ser tratado como relevante, ele deveria ser citado mais de uma vez e por autores diferentes.

\section{Procedimento de análise dos resultados}

Os fatos históricos selecionados foram organizados em ordem cronológica. A escolha pela ordem temporal teve a finalidade de descrever sequencialmente os eventos históricos e mostrar como foram construídos alguns aspectos culturais e simbólicos da fogueira junina. 
Após a ordenação dos fatos históricos, buscou-se relacioná-los com as considerações apresentadas pelos autores por meio de descrições comuns e comentários adicionais que ajudassem a entender a prática da fogueira junina. Esse procedimento permitiu identificar, de modo mais detalhado, os contextos, ambientes, ações (das pessoas em grupos) e as consequências que perpassaram alguns fatos envolvendo a fogueira junina.

Por fim, esse relato histórico foi analisado e interpretado a partir dos princípios da Análise do Comportamento, buscando tratar a fogueira de São João como prática cultural e rede relacional simbólica. Foram identificadas e descritas algumas relações comportamentais que perpassaram a fogueira junina, como prática cultural, ao longo da História. Foram lançadas também algumas hipóteses de como os grupos lidavam com a fogueira, considerando a rede relacional simbólica que estabelecia com outros eventos.

\section{Resultados e Discussão}

\section{Os marcos celestes e as práticas dos povos antigos}

Os ciclos solares e lunares têm sido observados pela Humanidade há séculos e definiram muitas práticas sociais e produtivas dos povos antigos (Lima, 1971). É bem provável que comportamentos relacionados a esses ciclos tenham sido selecionados pela exposição às contingências e pela observação da natureza, garantindo a muitos grupos sobreviverem e se adaptarem a diferentes regiões e climas. O desenvolvimento da agricultura, da estocagem de grãos e da domesticação animal ampliou tal capacidade adaptativa e fortaleceu o controle que os ciclos naturais exerciam sobre as práticas humanas; o Peret $^{2}$ é um exemplar disso (Rangel, 2008). Em todos os tempos, várias civilizações foram beneficiadas por organizarem processos produtivos com base nas ciclicidades naturais (Lima, 1971).

Diversos povos adotaram as configurações celestes - como a posição do sol, da lua e das constelações - como elementos que demarcaram o início

2 Semeadura do Antigo Egito que coincidia com as cheias do Nilo. e o fim das atividades do grupo (Lima, 1971). Esses marcos celestes funcionaram como estímulos discriminativos para que os povos se engajassem em algumas atividades (como caçar, plantar e colher) e obtivessem êxito na produção de bens (que operariam como reforçadores positivos) ou minimizassem prejuízos (como perdas na lavoura, o que seria uma condição reforçadora negativa). Observar os sinais e regularidades no céu, possivelmente, ampliou as chances de identificar as estações, de preparar a terra no momento adequado e de produzir boas colheitas, contribuindo para sobrevivência do grupo (Lima, 1971; Rangel, 2008).

Provavelmente, algumas civilizações arranjaram condições especiais para estabelecer e intensificar o controle que os marcos celestes exerciam sobre as contingências produtivas e reprodutivas do grupo. Uma das formas de fortalecer essa função discriminativa foi relacionar arbitrariamente os marcos celestes às crenças místicas e práticas culturais (Cascudo, 1956; Lima, 1971). Assim, rituais e festividades foram criados com base nesses eventos celestes e estabeleciam contingências que organizavam e mantinham os comportamentos produtivos, reprodutivos, de proteção e de coesão do grupo (Guerin, 1992; Chianca, 1991, 2007; Lima, 1971). O Lammas no equinócio de outono celebrava as primeiras colheitas celtas, venerava Lugh e era comemorado com a troca de pães e grãos (Rangel, 2008). As noites de lua cheia de outubro eram dedicadas à Demeter e repletas de incentivos sexuais (Chevitarese \& Penna, 2001); ocorrências análogas a essas eram frequentes em outros povos (Lima, 1971).

O governo e a religião, como agências de controle (Sidman, 2003; Skinner, 1953), contribuíram de modo importante na instalação e manutenção dos comportamentos relacionados aos eventos celestes quando: formularam verbalmente preceitos e regras, criaram cerimoniais religiosos, oficializaram calendários (que coincidiam com esses marcos celestes), ensinaram deliberadamente essas práticas e consequenciaram o engajamento do grupo nessas práticas (Lima, 1971; Rangel, 2008). No Lammas, a troca de grãos era permitida no equinócio de outono e a recusa em participar era punida com maldições (pelo clero) e a expulsão do grupo. Nas festividades à Demeter, as sacerdotisas prescreviam regras de incentivo às relações sexuais e os homens 
eram dispensados dos deveres públicos. Em ambos os casos, a religião e o governo manejaram contingências que corroboraram para a produção e reprodução do grupo. Essa descrição sugere uma aproximação com a proposta do Materialismo Cultural, ao considerar que práticas de nível estrutural (governo) e superestrutural (religião) produzem condições e consequências para manter a infraestrutura (produção de bens e sobrevivência) (Harris, 2001; 2007; Melo \& de Rose, 2015).

\section{Os rituais de fertilidade}

Os festivais de fertilidade são exemplares interessantes das convenções estabelecidas entre os marcos celestes e as práticas culturais. Civilizações ao longo de toda a História organizaram festas e rituais regidos por solstícios e equinócios (Chianca, 1991; Lima, 1971; Rangel, 2008; Trigueiro, 1995) e que visavam celebrar a fecundidade da terra e as divindades associadas a ela. "Imitando a natureza", as culturas sobrepuseram condições de incentivo à fertilidade a essas festas por meio de rituais, prescrições e permissões sexuais (Chevitarese \& Penna, 2001; Chianca, 1991; Rangel, 2008).

As condições providas pelos festivais da fertilidade articularam um refinado arranjo de contingências sociais. Ao participar desses festejos, os membros podiam transmitir verbalmente tradições intra e entre gerações, fortalecer laços sociais e políticos, articular esforços coletivos (no plantar, colher, caçar e pescar), reafirmar crenças e estabelecer uma regulação produtiva (como divisão de tarefas) e reprodutiva (como casamentos por acordos) (Chianca, 1991; Guerin, 1992; Lima, 1971; Rangel, 2008).

A religião e o governo atuaram no fortalecimento dessas relações comportamentais pela ampliação do controle de estímulos - como leis e doutrinas (Todorov, Martone, \& Moreira, 2005) - e pela consequenciação das ações individuais (Sidman, 2003; Skinner, 1953), as quais abrangiam desde aprovação, prestígio, atribuição de funções políticas/religiosas (que funcionavam como reforçadores positivos) até reclusão, interditos sexuais e expulsão do grupo (que poderiam ser eventos punidores). É bem provável que essas contingências produziram efeitos na produção (como colheitas profícuas) e reprodução (como aumento da população) e beneficiavam a sobrevivência dessas culturas (Guerin, 1992).
Os festivais de fertilidade dos povos celtas, bascos, egípcios, persas e sumérios ocorriam próximo ao solstício que marcava o início do verão no Hemisfério Norte (Chianca, 1991, 2009; Lima, 1971; Rangel, 2008; Trigueiro, 1995). Essas solenidades atravessaram gerações e foram incorporadas em outras culturas (como a greco-romana), preservando algumas peculiaridades (Chianca, 1991; Lima, 1971; Rangel, 2008): a reverência às divindades ligadas à fertilidade, a abundância de alimentos durante as comemorações, o incentivo a interações sexuais e a prática de atear fogueiras.

A veneração dos deuses da fecundidade era manifesta por meio de práticas consideradas sagradas (como ritos e cerimônias) e profanas (como festas e orgias) (Chianca, 1991; Lima, 1971; Rangel, 2008). Essas práticas estabeleceram, possivelmente, algumas relações funcionais importantes para os povos antigos, como apoio social, manutenção das forças produtivas e crenças e regulação e transmissão de práticas (Guerin, 1992; Guerin, 1998; Todorov, Martone, \& Moreira, 2005). Quando os celtas cultuavam os deuses da fertilidade durante os festivais, eles recebiam as benções dos sacerdotes e, somente depois disso, faziam acordos produtivos e iniciavam o plantio; os que não fossem abençoados, recebiam maldições, eram boicotados no plantio e não conseguiam recrutar camponeses para a lavoura.

A fartura de alimentos foi outro componente dos festivais de fertilidade (Rangel, 2008; Cascudo, 2000). Servir mesas fartas foi uma forma de retribuir a fertilidade da terra, aproximar famílias, celebrar as boas colheitas e pedir a prosperidade para o próximo plantio (Cascudo, 1956; Chianca, 1991; Lima, 1971). A abundância de alimentos pode ser dimensionada, também, em aspectos sociais e simbólicos. No âmbito social, celebrar ao redor de mesas criou contingências particulares para agregar pessoas, favorecer a socialização, evidenciar a posição que determinada família ocupava no grupo ${ }^{3}$ e estabelecer pactos (Chianca, 2007; Guerin, 1992). Sob uma perspectiva simbólica (de Rose, 2016), apresentar uma mesa repleta de produtos da terra pareceu participar de uma complexa rede relacional de estímulos que envolviam fartura, bênçãos e

3 As famílias donas das terras que ofereciam os alimentos para os festivais de fertilidade. 
"graças" concedidas pelas divindades da fertilidade (Cascudo, 1956; Lima, 1971). Essa interpretação pode justificar o fato de que famílias romanas que ostentavam banquetes nos festivais de Juno eram tidas como agraciadas e com privilégios divinos, o que lhes conferia mais poder e prestígio social (Rangel, 2008).

Os festivais de fertilidade também criaram condições que facilitaram as interações sexuais (Chianca, 1991; Rangel, 2008). O governo e a religião atuaram para prover e ampliar os controles de estímulos e as consequências de mais interações amorosas e relações sexuais ${ }^{4}$ (Chevitarese \& Penna, 2001; Guerin, 1992). Alguns comportamentos que integravam as práticas sexuais passaram a ser arbitrados por regras da cultura, produzindo complexas relações respondentes-operantes (de Rose, 2016). Na Grécia Antiga, algumas interações sexuais estavam sob controle de múltiplos aspectos, como contexto (ritual de fertilidade), as regras (as jovens deveriam trazer vasos com cereais), as redes relacionais simbólicas e as estimulações fisiológicas (induzidas, inclusive, por substâncias) (Lima, 1971; Rangel, 2008).

\section{A fogueira nos rituais de fertilidade}

Atear fogueiras foi, possivelmente, uma das práticas centrais dos festivais de fertilidade (Chianca, 2009; Lima, 1971; Rangel, 2008). Por meio desse fogo, os povos antigos ampliaram a fertilidade da terra, adoraram os deuses, prepararam alguns alimentos e intensificaram as relações amorosas (Chianca, 1991; Lima, 1971).

Como prática cultural, a fogueira dos rituais de fertilidade requeria uma gama de comportamentos entrelaçados (Todorov, Martone, \& Moreira, 2005). Enquanto uns selecionaram a madeira, outros a empilharam em formatos específicos e alguns acenderam o fogo de uma forma particular, seguindo as tradições (Chianca, 1991); e essas ações indivi-

\footnotetext{
4 Durante os festivais de fertilidade, as praças e ruas eram enfeitadas e rituais, magias e adivinhações eram feitos. Essas práticas visavam estimular as interações amorosas e sexuais, por meio de relações de controle de estímulos para os comportamentos sexuais do grupo. Consequências como aprovação, bênçãos, concessões morais e prestígio social poderiam fortalecer essas práticas.
}

duais eram coordenadas geralmente por costumes ${ }^{5}$ e prescrições (Todorov, Martone, \& Moreira, 2005). É bem provável que as consequências que selecionaram esse entrelaçamento de contingências tenham sido de natureza produtiva, considerando que povos que queimavam madeiras e ramagens no solstício de verão (a) ficavam com terrenos adubados (técnica da oivara) (Cascudo, 1956, 2000; Chianca, 1999; Rangel, 2008), aumentando as chances de boas colheitas e; (b) espantavam possíveis pragas, pois as fogueiras elevavam a temperatura próxima às plantações (Cascudo, 1956, 2000; Rangel, 2008), minimizando perdas agrícolas.

A fogueira dos rituais de fertilidade promoveu condições particulares para interações entre os membros do grupo (Cascudo, 1956, 2000; Chianca, 1991; Rangel, 2008) e exerceu várias funções nos contextos sociais. Uma especulação seria que essa fogueira tivesse exercido um controle condicional sobre algumas interações do grupo: somente quando essa fogueira estava acesa ( $S$ condicional), o dono da terra podia ter acordos (resposta) com a mão-de-obra ( $S$ discriminativo), sendo consequenciados por maiores chances de recrutar camponeses e obter boas colheitas (consequências); a fogueira estabelecia, ainda, condições ( $S$ condicional) para que cidadãos interagissem sexualmente (resposta) com os pares ( $S$ discriminativo) e tivessem maiores oportunidades de envolvimento sexual (consequência) (Chianca, 1991; Guerin, 1992). Outra possibilidade seria dessa fogueira ter exercido uma função reforçadora condicionada: ao construí-la e acendê-la, os membros obtiveram reforços sociais (como aprovação, afeto, proteção, prestígio social e cooperação), ganhavam a benção dos sacerdotes, livravam-se das desgraças e tinham acesso às festividades, às refeições e aos parceiros sexuais (Cascudo, 1956; Chianca, 1991; Guerin, 1992; Rangel, 2008).

Uma das principais finalidades para o uso do fogo nos rituais de fertilidade talvez tenha sido seu alcance como símbolo. A Figura 1 apresenta as re-

5 O costume pode ser descrito como uma regra transmitidas entre gerações. Na cultura celta, o costume era selecionar madeiras nobres e acender a fogueira quando a lua estivesse no ponto alto do céu. Já na cultura grega, os ceifeiros que construíam a fogueira e somente os sacerdotes podiam acendê-la e, com isso, invocar os espíritos e afugentar os maus agouros. 


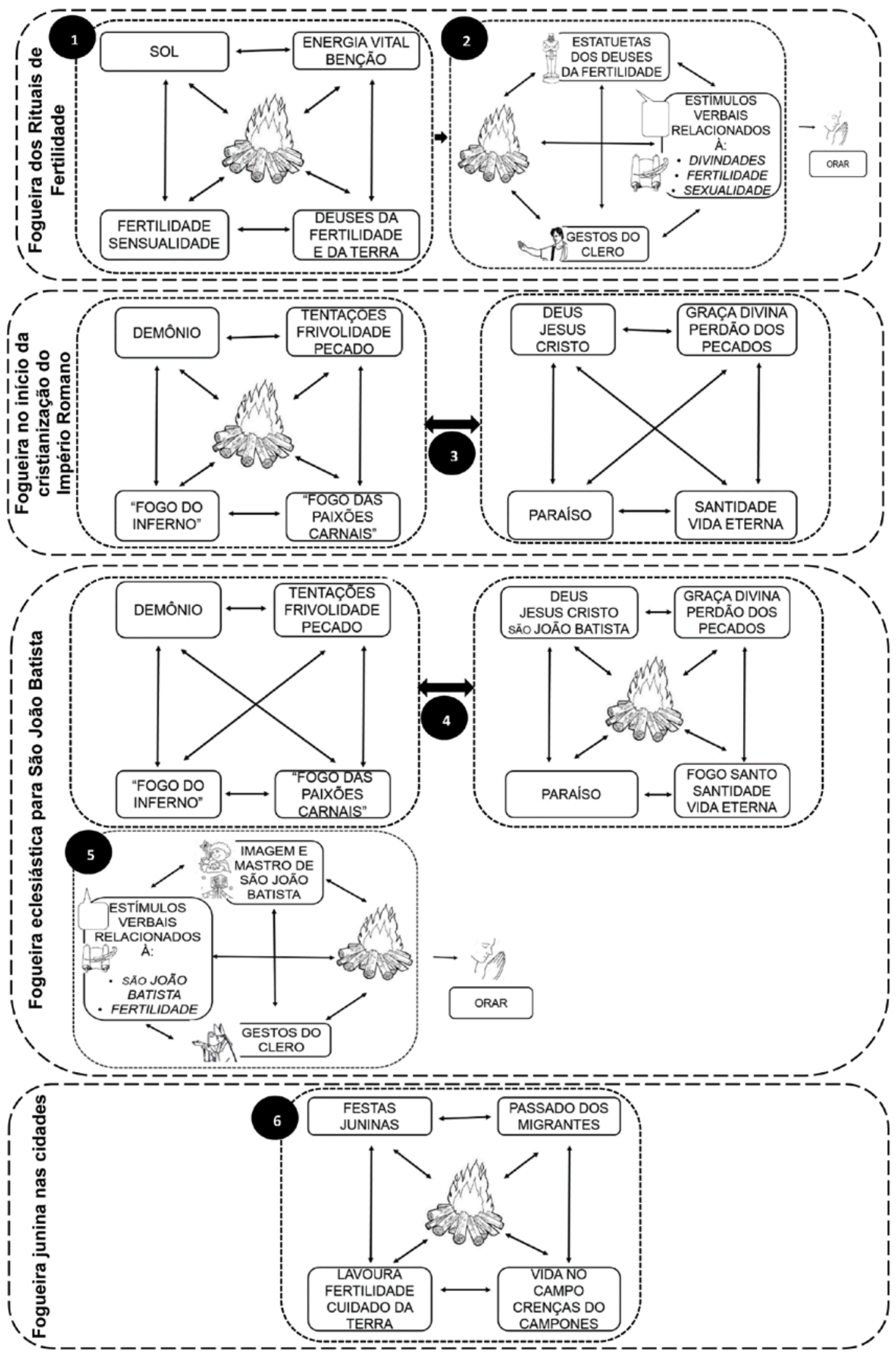

Figura 1. Diagrama esquemático e simplificado de redes relacionais simbólicas que podem ter envolvido a fogueira junina ao longo da História. 
des relacionais simbólicas em que a fogueira pode estar envolvida nos diversos momentos históricos; os diagramas contidos nessa Figura serão explorados ao longo do artigo.

Durante esses festivais, as fogueiras passaram a ser tratadas como se fossem canais de comunicação entre homens e deuses, como "fontes" de energias/ bênçãos ou como a presença da própria divindade (Chianca, 1991). Estudos como o de Rangel (2008), Lima (1971) e Chianca (2007) ofereceram pistas de algumas relações que poderiam integrar essa rede relacional simbólica de estímulos: as fogueiras foram relacionadas ao sol, ao calor, à energia, à sensualidade, à fertilidade, aos deuses da fertilidade, à fartura, as bênçãos e aos impulsos sexuais; o item 1 da Figura 1 esquematizou, de modo simplificado, essa rede. Essa rede simbólica foi condicionada a um contexto: não era uma fogueira qualquer, disposta em certo lugar e acesa de qualquer jeito, mas somente a fogueira dos rituais de fertilidade que, de fato, participou dessa rede simbólica e foi capaz de evocar alguns comportamentos.

Fazer preces junto à fogueira foi uma prática bastante comum nos rituais de fertilidade (Chianca, 1991, 2009). Esse operante podia ter sido aprendido por meio das contingências do grupo e por uma modelação mais direta (Catania, 1999; Skinner, 1953). Contudo, esse ato podia ter sido derivado também da transferência de função discriminativa entre estímulos que participavam dessa rede simbólica. Estímulos verbais (relacionados às divindades, à fertilidade e aos impulsos sexuais), estatuetas de veneração e gestos do clero podem ter participado de relações de equivalência com a fogueira (Chianca, 1991; de Rose, 2016; Sidman, 1994), de modo a evocar orações. O item 2 da Figura 1 representa essas relações.

Outra possibilidade é a de que a rede simbólica da fogueira compartilhasse de funções eliciadoras condicionadas (Dougher et al., 1994). O fogo foi simbolicamente atrelado à sensualidade, aos impulsos carnais, ao "calor das paixões" e ao próprio ato sexual (Chevitarese \& Penna, 2001; Chianca, 1991). É provável que as culturas tenham criado condições especiais para que acender a fogueira nos rituais de fertilidade aumentasse práticas sexuais, como nas fogueiras acesas ao deus $\mathrm{Baco}^{6}$ (Guerin, 1994; Rangel, 2008).

\section{A invenção da festa de São João}

No século IV (D.C), o cristianismo tornou-se a religião oficial de Roma e promoveu mudanças importantes na organização do império (Chianca, 1991, 2009; Lima, 1971; Proença, 2015). Como agência de controle em ascensão, a Igreja Católica realizou intensos esforços para abolir as práticas politeístas e instaurar novas condutas religiosas. Esses esforços podem ser descritos pelo manejo de contingências: (a) coercitivas, de modo que atos pagãos fossem consequenciados por castigos físicos, humilhação pública e condenação de pecados; e, ao mesmo tempo, (b) de reforçamento quando atos de "conversão" e adesão cristã (como admissão pública da fé, negação dos deuses e dos atos profanos e o batismo) eram consequenciados por privilégios sociais, participação na comunidade cristã e a absolvição de infrações e pecados (Chianca, 1991, 2009; Proença, 2015; Sidman, 2003; Skinner, 1953).

A doutrinação em massa, a imposição dos rituais cristãos e a punição dos atos profanos não garantiu que as práticas religiosas do Império Romano fossem extintas completamente (Chianca, 2007, 2009). Alguns grupos realizaram cultos às escondidas, como forma de contracontrole à dominação católica (Proença, 2015). Essa resistência poderia ser compreendida, ao menos em parte, pelo fato de que o catolicismo dispunha de reforçadores pouco eficientes para modificar essas práticas (tais como a vida eterna e absolvição dos pecados), contrariamente às consequências primárias e de alto valor reforçador (como sexo) que foram obtidas nos rituais profanos (Chianca, 1991, 2009; Guerin, 1992; Skinner, 1953).

O contato dos valores cristãos com as práticas pagãs produziu confrontos e sincretismos (Chianca, 1991, 2007, 2009; Proença, 2015; Rangel, 2008). Por um lado, possivelmente houve conflitos ideológicos e de conduta: várias contingências previstas pelo catolicismo foram incompatíveis com as propostas pelo politeísmo romano. Por outro, produziu um processo em que alguns componentes da

6 O fogo inaugurava os bacanais romanos, que findavam quando a fogueira estava apagada. 
religião romana foram preservados, enquanto os componentes da fé católica foram integrados e sobrepostos às práticas religiosas do povo (Cascudo, 1956, 2000; Chianca, 2009; Lima, 1971; Proença, 2015; Rangel, 2008).

Essa tentativa de integrar o "sagrado" católico e o "profano" romano foi inicialmente combatida, mas não surtiu efeito (Chianca, 2009; Proença, 2015). A alternativa para a Igreja Católica foi prover contingências que pudessem compatibilizar e regular essas práticas sincréticas, de modo a manter seu controle $^{7}$ (Cascudo, 1956; Chianca, 2009; Rangel, 2008; Skinner, 1953). Assim, o panteão dos deuses greco-romanos foi adequado ao paraíso dos santos e os rituais foram substituídos pelas liturgias cristãs (Chianca, 2007; Proença, 2015).

O catolicismo também incorporou a definição das festividades por meio de marcos cósmicos, que era uma prática recorrente dos povos pagãos (Cascudo, 1956; Proença, 2015; Rangel, 2008; Trigueiro, 1995). Tendo como referência o Hemisfério Norte, a Igreja Católica definiu suas principais festas com base nos ciclos solares e lunares, como a Páscoa (a ressurreição de Cristo) no domingo após a primeira lua cheia primaveral e o Natal (o nascimento de Cristo) no solstício de inverno. A estratégia de substituir as festas profanas por cristãs (Chianca, 1991, 2007, 2009; Proença, 2015) integrou as medidas que enfraqueciam as práticas pagãs e, em contrapartida, favoreciam condições para aprender as condutas católicas.

O solstício de verão no Hemisfério Norte demarcava o início de um ciclo agrícola e era celebrado com os festivais e práticas de fertilidade, que favoreceram por muito tempo a sobrevivência dos povos (Guerin, 1992; Rangel, 2008). Para combater esses festivais e rituais, o clero católico investiu esforços nos mecanismos de controle (por prescrições e vigilância moral) e intensificou as consequências para os atos compatíveis e os incompatíveis com os valores cristãos (Chianca, 1991; Proença, 2015; Sidman, 2003; Skinner, 1953). Algumas prá-

7 Essa estratégia foi eficiente para disseminar a fé cristã e permitiu mais adeptos em Roma e na extensão do império. Um exemplo é a prática de realizar procissões que foi herdada dos romanos quando andavam pelas ruas com as estátuas das divindades em andores adornados. ticas desses festivais, como a liberação sexual e a adivinhação, concorriam com o projeto cristão e representaram uma ameaça real ao controle católico (Chianca, 1991, 2007, 2009; Proença, 2015).

As investidas coercitivas não foram suficientes para erradicar os festivais de fertilidade (Chianca, 2009; Proença, 2015; Rangel, 2008). A alternativa para controlar essas práticas e adequá-las às finalidades cristãs foi associar o solstício de verão ao nascimento de São João Batista (Chianca, 1991, 2009; Lima, 1971; Proença, 2015; Trigueiro, 1995). Deste modo, foram inauguradas as festas joaninas $^{8}$ (ou festejos de São João); alguns historiadores têm divergido sobre a "invenção" dessa festa e tem apontado que foi um resquício direto dos festivais de fertilidade (Candido, 2001; Proença, 2015; Rangel, 2008).

A escolha em celebrar o nascimento de São João Batista no solstício de verão não foi totalmente arbitrária e encontrou respaldo religioso ${ }^{9}$ (Cascudo, 1956; Chianca, 1991, 2009; Lima, 1971; Proença, 2015; Rangel, 2008). A oficialização do culto a São João Batista foi um passo importante para assegurar controle de alguns comportamentos pela Igreja Católica (Chianca, 1991, 2007, 2009; Proença, 2015). Nos rituais de fertilidade (em que práticas pagãs eram recorrentes), a inserção de componentes cristãos poderia facilitar que comportamentos profanos fossem enfraquecidos e as condutas cristãs fossem reforçadas.

Os povos do Império Romano tiveram certa facilidade em assimilar a proposta e estenderam as práticas das festas de fertilidade ao culto católico (Cascudo, 1956; Lima, 1971; Rangel, 2008). Um dado interessante foi que a iconografia de São João Batista compartilhava de várias similaridades físicas com os deuses da fertilidade, como Adônis

8 O termo "junina" remeteu ao deus Juno e devia ser abolida do vocabulário. A expressão "joanina” advém desse esforço para substituir a referência a Juno por São João Batista.

9 A bíblia descreve São João Batista como um profeta que nasceu seis meses antes do primo Jesus Cristo; mesmo intervalo entre o solstício de verão e o de inverno (Natal). A tradição conta que mãe de Jesus foi avisada do nascimento de João por uma fogueira, o que permitiu interseccionar as festas da fertilidade e o culto cristão. Os católicos referiam a vida desse santo a elementos agrícolas, o que aproximou dos festivais que celebravam as colheitas. 
(Chianca, 1991, 2009); o que leva a especular que esses comportamentos podem ter sido facilitados também por uma possível generalização de estímulos (Catania, 1999) entre o Batista e esses deuses.

Outra consideração é que o catolicismo ensinou deliberadamente a relação entre São João Batista e elementos desses festivais (como fecundidade, a terra e a fartura), na tentativa de enfraquecer as relações com os deuses da fertilidade (Chianca, 1991,2007, 2009; Rangel, 2008; Lima, 197; Proença, 2015). Uma interpretação permitiria admitir que São João Batista foi integrado à uma rede relacional simbólica (de Rose, 2016; Sidman, 1994) dos festivais de fertilidade, compartilhando as funções dos estímulos dessa rede. Isso explicaria, de alguma forma, porque eram feitas as mesmas práticas dos rituais de fertilidade no culto católico. Na Idade Média, a festa junina manteve algumas práticas dos festivais de fertilidade, como acender fogueiras e bênçãos na lavoura (Rangel, 2008; Proença, 2015; Lima, 1971). Na Sardenha do século XX permaneceu o costume de visitar jardins e plantar flores, embora se cultuasse o Batista (Rangel, 2008). Aldeias italianas do século XVIII mantiveram atos de aproximação amorosa análogos aos festivais de fertilidade (Lima, 1971; Rangel, 2008).

\section{Ressignificando os fogos profanos}

A reinvenção das festas juninas teve êxito na extensão das práticas pagãs (dos festivais) para a veneração a São João Batista. Em contrapartida, essa condição criou desafios para a Igreja Católica, especificamente porque a fogueira foi atrelada a uma simbologia de fertilidade, de sensualidade e de práticas sexuais. Como dissociar a fogueira como símbolo dos desejos carnais? (Chianca, 1991, 2007, 2009)

O plano inicial foi alterar simbolicamente a fogueira, tornando-a um elemento antagônico ao cristianismo (Cascudo, 1956; Chianca, 1991, 2009). Deste modo, as prescrições católicas visaram relacionar essa fogueira com eventos verbais e não-verbais de valor religioso negativo (Guerin, 1992), como o "fogo do inferno", demônio, tentações, perdição, pecado, frivolidade, "o fogo das paixões carnais" e a destruição da obra do Criador (Cascudo, 1956; Chianca, 1991, 2007, 2009).

Um olhar analítico-comportamental permitiria interpretar que a Igreja Católica estabeleceu condições para que a fogueira integrasse uma rede relacional de estímulos que se opunha a redes relacionais que envolviam Jesus Cristo, a vida eterna, a graça divina e o perdão dos pecados, como esquematicamente apresentado no item 3 da Figura 1. Ao compor essa "nova" rede relacional simbólica, supõe-se que a fogueira dos rituais de fertilidade compartilhava das funções dos outros estímulos da classe (demônio, inferno, dentre outros), de modo que qualquer ato envolvendo essa fogueira seria tratado como pecaminoso (Chianca, 1991, 2007, 2009; Lima, 1971); logo, fazer esses atos produziriam punições e seria reforçado (negativamente) quando se livrava deles (de Rose, 2016; Skinner, 1953).

\section{A fogueira de São João}

A Igreja Católica insistiu por um tempo em atribuir conotações pejorativas às fogueiras dos rituais de fertilidade. Essa estratégia não foi efetiva para extinguir essa prática e só foi resolvida no Concílio de Trento (1545-1563), quando a Igreja Católica admitiu essa fogueira como fogo eclesiástico ${ }^{10}$ (Chianca, 1991, 2007, 2009; Proença, 2015; Rangel, 2008).

Essa decisão inaugurou o fogo santo de São João Batista e facilitou construir uma nova simbologia para a fogueira. Algumas contingências arranjadas pelo catolicismo permitiram que essa fogueira alterasse sua função, passando da rede relacional simbólica que envolvia elementos profanos para uma rede relacional simbólica com elementos "sagrados" (vide item 4 da Figura 1) (de Rose, 2016). Como observado no item 5 da Figura 1, a fogueira de São João passou a ser tratada virtualmente como um fogo "descido dos céus" e a própria presença de São João Batista, evocando orações, purgações, o controle dos desejos e a submissão ao clero (Cascudo, 1956; Chianca, 2007, 2009; Lima, 1971; Rangel, 2008).

A dominação do catolicismo consolidou a fogueira como o símbolo eclesiástico nas festas juninas (Chianca, 2007, 2009; Lima, 1971; Proença, 2015; Rangel, 2008). Contudo, algumas crendices e práticas populares persistiram e foram sobrepostas

10 Os fogos eclesiásticos estavam relacionados simbolicamente a purificação, a dominação das paixões, a santidade e a restauração da ordem divina; não é como o fogo pagão que destrói a obra divina, mas um fogo sagrado que aproxima o homem ao Criador. 
a esse fogo sagrado (Cascudo, 1956; Chianca, 1991, 2009). Acredita-se que São João Batista permanecia dormindo durante seu aniversário e que a fogueira "acordava o santo", de modo que descesse dos céus, abençoasse as lavouras e festejasse com seus devotos; a cantiga "Acordai, João" faz alusão a essa crença (Cascudo, 2000; Chianca, 1991; Rangel, 2008). Esse enredo se assemelhou ao de Adônis que descia sobre as lavouras e gozava das oferendas à luz da fogueira (Lima, 1971; Rangel, 2008). Alguns indícios antropológicos sustentaram a ideia de que os relatos míticos dos pagãos foram mantidos e coube a Igreja Católica arranjar contingências verbais para adequá-los (Guerin, 1992; Rangel, 2008).

As festas juninas preservaram vários resquícios dos festivais pagãos, como as danças, os banquetes com produtos da terra, as investidas amorosas e a prática de atear fogueiras (Cascudo, 1956; Chianca, 1991, 2009; Lima, 1971; Proença, 2015; Rangel, 2008). Essas práticas foram especialmente manipuladas em suas relações de controle de estímulos e consequências para torná-las moralmente mais aceitáveis e compatíveis com a doutrina católica (de Rose, 2016; Chianca, 2007, 2009; Guerin, 1992; Rangel, 2008).

\section{A fogueira de São João nas cidades}

As revoluções industriais e as mudanças nos sistemas produtivos promoveram uma intensificação do êxodo rural e o aumento de pessoas morando em centros urbanos (Chianca, 1991; Lima, 1971; Proença, 2015). As mudanças nas contingências produtivas exigiram que os migrantes do campo se adaptassem às cidades, entrassem em contato com outros artefatos tecnológicos e interagissem de formas muito distintas às estabelecidas no contexto agrário. O conflito entre as culturas do campo e da cidade foi tamanho que foi expresso por caricaturas do homem moderno da cidade e o homem matuto da fazenda, como o Jeca Tatu de Monteiro Lobato (Candido, 2001; Rangel, 2008).

Durante o êxodo rural, algumas práticas culturais do campo foram transpostas para o contexto urbano. As festas juninas que eram realizadas nas fazendas foram reproduzidas nas vilas e centros comunitários (Candido, 2001; Cascudo, 1956; Chianca, 1991, 2009; Trigueiro, 1995), sendo mantidas e reforçadas entre as pessoas das comunidades de migrantes.
Contudo, os festejos de São João não celebravam mais as colheitas e a fertilidade da terra, nem a fogueira era mais tratada como "fogo do céu", do "acordar João" ou das bênçãos sobre as lavouras (Candido, 2001; Cascudo, 1956, 2000; Chianca, 1991; Rangel, 2008). As festas juninas serviam, agora, para rememorar o passado, a simplicidade do camponês, a proximidade do homem com a terra e a religiosidade que atravessava as práticas do homem da roça (Candido, 2001; Proença, 2015; Rangel, 2008; Trigueiro, 1995).

Esse "novo significado" da festa e da fogueira junina poderia ser descrita a partir de uma rede relacional. Sob contexto urbano, a fogueira junina pareceu participar de uma rede relacional simbólica de estímulos que envolviam a lavoura, o passado dos migrantes, o cuidado com a terra e as crenças juninas dos camponeses. O item 6 da Figura 1 indica esquematicamente essa hipótese de rede relacional.

\section{Considerações finais}

Acender a fogueira de São João pode ser compreendido para além de um ato devocional (Candido, 2001; Chianca, 1991, 2009; Rangel, 2008). Nesse trabalho, a fogueira junina foi alvo de descrição e análise comportamental (de Rose, 2016; Todorov, Martone, \& Moreira, 2005), permitindo lançar interpretações que podem vir a complementar considerações já feitas por historiadores, sociólogos, antropólogos e folcloristas.

Uma conclusão foi que as práticas envolvidas nas festas de São João derivaram de diversas culturas, com origens que remontam aos festivais de fertilidade. Essas festividades articularam a cooperação produtiva, a coesão do grupo e o incentivo sexual, beneficiando a subsistência e a sobrevivência das culturas de vários povos antigos (Guerin, 1992, 1994).

A fogueira foi como um dos elementos centrais dos festivais de fertilidade (Candido, 2001; Chianca, 1991, 2009; Lima, 1971). Essa fogueira pode ter funcionado como componente discriminativo de várias condutas dos grupos, de práticas nos festivais de fertilidade até os atos compatíveis com ideais católicos (Proença, 2015; Rangel, 2008).

Outra possibilidade apontada nesse trabalho foi que essa fogueira pode ter integrado redes rela- 
cionais simbólicas. Nos rituais de fertilidade, essa rede poderia ter envolvido estímulos relacionados à fecundidade, às energias da terra e aos impulsos sexuais. A ascensão do catolicismo construiu novas simbologias para essa fogueira: inicialmente, a fogueira foi integrada à uma rede relacional que era antagônica aos ideais cristãos e depois foi admitida como fogo eclesiástico, participando de uma rede relacional simbólica com estímulos católicos. Esse exercício que foi feito parece ser relativamente recente nos estudos comportamentais em cultura e podem ser explorados em outros estudos (de Rose, 2016).

O presente trabalho apresentou uma tentativa de interpretar a fogueira de São João, sob a perspectiva da Análise do Comportamento. Essa descrição e interpretação permitiu especular possíveis processos comportamentais que abrangeram atear fogueiras na noite de São João. Outras análises são possíveis e devem ser exploradas e investigadas.

Os conhecimentos da História, da Sociologia, da Antropologia e do Folclore favoreceram que as análises sobre a fogueira de São João estivessem mais situadas em contextos históricos, como propõe Guerin $(1992,1994,1998)$. A interface da Análise do Comportamento com essas ciências humanas foi promissora nesse estudo e pareceu indicar um espaço profícuo para ampliar a compreensão das práticas consideradas populares.

\section{Referências}

Amaral, R. C. M. P. (1998). Festa à brasileira - significados do festejar no país que "não é sério". Tese de doutorado, Universidade de São Paulo, São Paulo.

Andery, M. A. P. A., Micheletto, N., \& Sério, T. M. de A. P. (2005). A análise de fenômenos sociais: Esboçando uma proposta para a identificação de contingências entrelaçadas e metacontingências. Revista Brasileira de Análise do Comportamento, 1 (2), 149-165.

Andery, M. A. P. A. (2011). Comportamento e cultura na perspectiva da análise do comportamento. Perspectivas em Análise do Comportamento, 2, 203-217.

Barnes, D., \& Grey, I. (1996). Stimulus equivalence and attitudes. The Psychological Record, 46, 243-270.
Baum, W. M. (2000). Being concrete about culture and cultural evolution. In F., Tonneau \& N. S., Thompson (Orgs.), Perspectives in Ethology, Evolution, Culture, and Behavior (pp. 181-212). New York: Springer.

Biglan, A. (1995). Changing cultural practices: a contextualist framework for intervention research. Reno, NV: Context Press.

Brunkow, F. (2014). Análise do comportamento e evolução cultural: relações entre as propostas conceituais de B. F. Skinner e S. S. Glenn. Dissertação de Mestrado. Curitiba: Programa de Pós-Graduação em Psicologia, Universidade Federal do Paraná.

Candido, A. (2001). Os parceiros do Rio Bonito: estudo sobre o caipira paulista e a transformação dos seus meios de vida. São Paulo: Livraria Duas Cidades.

Carrara, K., \& Zilio, D. (2016). Análise comportamental da cultura: contingência ou metacontingência como unidade de análise?. Revista Brasileira de Análise do Comportamento, 11(2).

Cascudo, L. C. (1956). Antologia do folclore brasileiro. São Paulo: Edição Martins.

Cascudo, L. C. (2000). Dicionário do folclore brasileiro. 9 ed. São Paulo: Global.

Catania, A. C. (1999). Aprendizagem (4a ed.). Porto Alegre: Artmed.

Chevitarese, A. L., \& Penna, F. (2001). A magia e religião no festival das Antestérias. História Revista, 6, 9-18.

Chianca, L. O. (1991). Viva São João: o santo e sua festa. Dissertação de Mestrado, Universidade Federal da Paraíba, João Pessoa, PB.

Chianca, L. O. (2007). Devoção e diversão: expressões contemporâneas de festas e santos católicos. Revista Anthropológicas, 18(2), 49-74.

Chianca, L.O. (2009). Chama que não se apaga. Revista de História da Biblioteca Nacional, 4(45), 10-30.

de Carvalho, M. P., \& de Rose, J. C. (2014). Understanding racial attitudes through the stimulus equivalence paradigm. The Psychological Record, 64, 527- 536.

de Rose, J. C. (2016). A Importância dos respondentes e das relações Simbólicas para uma análise comportamental da cultura. Acta Comportamentalia, 24(2), 201-220. 
de Rose, J. C., \& Bortoloti, R. (2007). A equivalência de estímulos como modelo do significado. Acta Comportamentalia, 15, 83-102.

Dittrich, A. (2004). Behaviorismo radical, ética e política: Aspectos teóricos do compromisso social. Tese de doutorado, Universidade Federal de São Carlos, São Carlos, SP.

Dougher, M. J., Augustson, E., Markham, M. R., Greenway, D. E., \& Wulfert, E. (1994). The transfer of respondent eliciting and extinction functions through stimulus equivalence classes. Journal of the Experimental Analysis of Behavior, 62, 331-351.

Geertz, C. (1973). The interpretation of cultures. New York: Basic Books.

Glenn, S. S. (1986). Metacontingencies in Walden Two. Behavior Analysis and Social Action, 5, 2-8.

Glenn, S. S. (1989). Verbal behavior and cultural practices. Behavior Analysis and Social Action, 7(1-2), 10-15.

Glenn, S. S. (2003). Operant contingencies and the origins of cultures. Em K. A. Lattal \& P. N. Chase (eds.), Behavior theory and philosophy (pp. 223-242). New York: Klewer Academic/ Plenum.

Glenn, S. S. (2004). Individual behavior, culture, and social change. The Behavior Analyst, 27 (2), 133-151.

Glenn, S. S., Malott, M. E., Andery, M. A. P. A., Benvenuti, M., Houmanfar, R. A., Sandaker, I., ... \& Vasconcelos, L. A. (2016). Toward consistent terminology in a Behaviorist approach to cultural analysis. Behavior and Social Issues, 25, 11-27.

Guerin, B. (1992). Social behavior as discriminative stimulus and consequence in social anthropology. The Behavior Analyst, 15(1), 31-41.

Guerin, B. (1994). Analyzing social behavior:behavior analysis and the social sciences. Reno, NV: Context Press.

Guerin, B. (1998). Religious behaviors as strategies for organizing groups of people: a social contingency analysis. The Behavior Analyst, 21, 53-72.

Harris, M. (2001). Cultural Materialism: the struggle for a science of culture. Updated Edition. Walnut Creek, CA: Altamira Press.

Harris, M. (2007). Cultural materialism and behavior analysis: common problems and radical solutions. The Behavior Analyst, 30, 37-47.

Haydu, V. B., Camargo, J., \& Bayer, H. (2015). Effects of preexperimental history on the formation of stimulus equivalence classes: A study with supporters of Brazilian soccer clubs. Psychology \& Neuroscience, 8, 385-396.

Lima, R. T. (1971). O Folclore das festas cíclicas. São Paulo: Irmãos Vitale.

Malott, M. E., \& Glenn, S. S. (2006). Targets of intervention in cultural and behavioral change. Behavior and Social Issues, 15, 31-56.

Melo, C. M., \& de Rose, J. C. (2012). Sobrevivência das culturas em Skinner: um diálogo com o materialismo cultural de Harris. Psicologia: Teoria e Pesquisa, 28, 119-128.

Mizael, T., dos Santos, S., \& de Rose, J. (2016). Contribuições do paradigma de equivalência de estímulos para o estudo das atitudes. Interação em Psicologia, 20(2).

Proença, W. L. (2015). Festa junina: origens históricas e culturais. Retirado 15 de agosto 2016, de http://www.ftsa.edu.br/site/index.php/ artigos/437-festa-junina-origens-historicas-e-culturais\#_ftnref 1

Rangel, L. H. V. (2008). Festas Juninas, festas de São João. São Paulo: Publishing Solutions.

Sampaio, A. A. S., \& Andery, M. A. P. A. (2010). Comportamento social, produção agregada e prática cultural: uma análise comportamental de fenômenos sociais. Psicologia: Teoria e Pesquisa, 26, 183-192.

Sénéchal-Machado, V., \& Todorov, J. (2012). A travessia na faixa de pedestre em brasília (df/ brasil): exemplo de uma intervenção cultural. Revista Brasileira de Análise do Comportamento, 4(2).

Sidman, M. (1994). Equivalence relations and behavior: a research story. Boston, MA: Authors Cooperative.

Sidman, M. (2000). Equivalence relations and the reinforcement contingency. Journal of the Experimental Analysis of Behavior, 74, 127-146.

Sidman, M. (2003). Coerção e suas implicações (M.A. Andery e T.M. Sério, Trans.). Campinas, SP: Ed. Livro Pleno. (Trabalho original publicado em 1989).

Skinner, B. F. (1953). Science and human behavior. New York: Free Press. 
Skinner, B. F. (1969). Contingencies of reinforcement: a theoretical analysis. New York: AppletonCentury-Crofts.

Skinner, B. F. (1974). About behaviorism. New York: Vintage Books.

Skinner, B. F. (1981). Selection by consequences. Science, 213, 501-504.

Todorov, J. C., Martone, R. C., \& Moreira, M. B. (2005). Metacontingências: comportamento, cultura e sociedade. Santo André: ESETec.

Trigueiro, O. M. (1995). Festejos juninos e os ritos de origem agrária. INTERCOM, 18(2), 153-156.

Vichi, C. (2004). Igualdade ou desigualdade em pequeno grupo: Um análogo experimental de manipulação de uma prática cultural. Dissertação de mestrado, Programa de Estudos Pós-Graduados em Psicologia Experimental: Análise do Comportamento, PUC-SP, São Paulo. 